Article

\title{
Stability and Cementation of the Surrounding Rock in Roof-Cutting and Pressure-Relief Entry under Mining Influence
}

\author{
Xizhan Yue ${ }^{1,2}$, Min Tu ${ }^{1, *}$, Yingfu Li ${ }^{1}$, Guanfeng Chang ${ }^{1, *(1)}$ and Chen $\mathrm{Li}^{1}$ \\ 1 School of Mining Engineering, Anhui University of Science and Technology, Huainan 232001, China; \\ xizhany@163.com (X.Y.); liyfaust@163.com (Y.L.); lichen3553@163.com (C.L.) \\ 2 Xinji No. 1 Mine, China Coal Xinji Energy Co., Ltd., Huainan 232001, China \\ * Correspondence: ahhn_2001@163.com (M.T.); guanfeng_chang@163.com (G.C.); \\ Tel.: +86-135-0057-1668 (M.T.); +86-199-5543-1989 (G.C.)
}

check for

updates

Citation: Yue, X.; Tu, M.; Li, Y.;

Chang, G.; Li, C. Stability and

Cementation of the Surrounding

Rock in Roof-Cutting and

Pressure-Relief Entry under Mining

Influence. Energies 2022, 15, 951.

https://doi.org/10.3390/en15030951

Academic Editors: Yulong Chen, Junwen Zhang, Jianhang Chen,

Xuejie Deng and Manoj Khandelwal

Received: 30 December 2021

Accepted: 25 January 2022

Published: 27 January 2022

Publisher's Note: MDPI stays neutral with regard to jurisdictional claims in published maps and institutional affiliations.

Copyright: (c) 2022 by the authors. Licensee MDPI, Basel, Switzerland. This article is an open access article distributed under the terms and conditions of the Creative Commons Attribution (CC BY) license (https:// creativecommons.org/licenses/by/ $4.0 /)$.

\begin{abstract}
The application of roof-cutting and pressure-relief gob-side entry retention plays a critical role in controlling the stability of the surrounding rock at the entry, easing continuity tension and improving resource recovery ratio. The excavation of the 360,803 airway in Xinji No. 1 Mine is affected by intense mining of the 360,805 working face. Hence, to address the stability problem of surrounding rock in the 360,803 airway, rock mass blast weakening theory was used in this study to analyze the blasting stress of columnar charged rock mass and obtain the radiuses of crushed, fractured, and vibration zones under uncoupled charging conditions. The reasonable array pitch, length, and dip angle of boreholes were determined according to the pressure-relief range of the blasting fracture. The migration laws of roof strata were explored based on a mechanical model of overlying roof strata structure on the working face. Subsequently, the horizon, breaking span, and caving sequence of hard roof strata were obtained to determine the roof-cutting height of this entry. On the basis of the theory of key stratum, the number of sequences at the roof caving limit stratum and hanging roof length in the goaf were calculated, the analytical solution to critical coal pillar width was acquired, the evaluation indexes for the stability of entry-protecting coal pillars were determined, and the engineering requirements for the $25 \mathrm{~m}$ entry-protecting coal pillars in the 360,803 airway were met. Moreover, various indexes such as roof separation fracture, displacement of surrounding rock, and loose circle of surrounding rock in the gob-side entry were analyzed. The stability and cementation status of surrounding rock in the 360,803 airway were evaluated, and tunneling safety was ensured.
\end{abstract}

Keywords: mining influence; roof cutting and pressure relief; cutting height; critical pillar width

\section{Introduction}

Nowadays, the exploitation of coal resources is continuously extending from the shallow part to the deep part of the Earth's crust. As a result, the mine pressure problem during mining activities is becoming increasingly serious, thus having major impacts on the safety of mine production [1-3]. Roof-cutting pressure-relief gob-side entry retention [4-6] cuts off the connection between the entry and goaf roofs and optimizes the mechanical structure of the surrounding rock in entry, thus having a crucial effect on maintaining the entry stability $[7,8]$.

The stability problem of entry roof in the roof-cutting pressure-relief gob-side entry retention process has been explored by many experts. He et al. [9] analyzed the mine pressure data of the working face through a roof-cutting entry retention test and found that the mine pressure on the working face has asymmetric distribution characteristics along the length direction. Wang et al. [10] constructed different rock strata by using similar materials such as gypsum powder, fine river sand, and barite powder, where six excavation steps along the coal seam strike were designed according to different entry retention scales. 
They studied the caving laws of overlying strata and the deformation characteristics of surrounding rock in the retained entry through visible light imaging, high-precision digital speckle imaging, and field artificial sketching. Liu et al. [11,12] analyzed the mechanical characteristics of the immediate roof in roof-cutting gob-side retained entry and established a mechanical model of the immediate roof by using the stress superposition principle and introducing the equivalent concentrated load of entry support to further probe the instability characteristics of structural plane-containing rock mass. They then revealed the instability mechanism under the action of stress wave. Hua et al. [13] conducted a 3D similar simulation test of roof-cutting pressure-relief gob-side entry retention and obtained the caving characteristics of overlying rock strata in the strike and dip directions and their migration laws. Gao et al. [14] combined mechanical analysis, numerical simulation, and engineering test to explore the deformation mechanism of gravel wall in the roofcutting entry retention at a thick coal seam and its control technique. They also probed the mining height effect of gangue impact during the entry retention process, clarified the deformation mechanism of gravel wall at a thick coal seam and its control emphasis, and presented the concept of multilevel control (impact prevention of dynamic pressure, relief of gentle pressure, and stable control of constant pressure). On the basis of the roof-cutting pressure-relief mechanism of shallow hole blasting gob-side entry retention, Chen et al. [15] combined LS-DYNA numerical simulation and theoretical analysis to examine the action mechanism of pilot hole and explore the influence of parameter selection on the blasting effect. Through theoretical analysis of mining pressure, FLAC3D numerical simulation, and field measurement of entry deformation, Zhang et al. [16] studied the roof-cutting pressure-relief gob-side entry retention mechanism of small coal pillars with a large mining height $(6 \mathrm{~m})$ and surrounding rock control in Fusheng Coal Mine of the Shanxi Lu'an Mining Group. Su et al. [17] used physical simulation and theoretical analysis to study the structure and migration laws of overlying strata in gob-side entry retained in a deep well and then established a mechanical model of key block at the gob-side entry. On the basis of mine ground pressure and theory of elastic mechanics, Xue et al. [18] constructed a mechanical calculation model of stope floor under periodic weighting considering the supporting effect of advanced roof caving from a working face along the dip direction on the overlying strata. Yang et al. [19] analyzed the roof structure and movement process under this technical condition; established a mechanical model of a roof with a short arm beam; derived the calculation formulas for the deformation of this roof in early, meta, and later phases by using the functional principle; and discussed the influential factors of the roof with a short arm beam in different deformation phases, as well as its sensitivity and control method. Yang et al. [20] studied the evolutionary process and stability control mechanism of a hard roof-cutting entry structure by using physical test, continuous-discontinuous medium simulation test, and mechanical analysis. Lin et al. [21] measured and analytically studied the evolution laws of 3D roof stress with the advancement of working face in the 3310 return airway of Jincheng Wangpo Coal Mine by using an improved hollow inclusion stress gauge with grouting anchorage in full boreholes.

The aforementioned studies have enriched findings on the stability of roof-cutting pressure-relief gob-side retained entry by providing a scientific basis for underground safety production. However, few studies are related to the stability and cementation of surrounding rock in roof-cutting pressure-relief entry during the mining process of the adjacent working face. Therefore, the number of sequences on roof caving limit stratum and hanging roof length of goaf were calculated based on the theory of key stratum, and the calculation formula for the critical coal pillar width was derived. Afterward, a mechanical model of overlying roof strata structure on the working face was established, the horizon, breaking span, and caving sequence of hard roof strata were calculated, and then the roofcutting height of entry was determined. The radiuses of crushed, fractured, and vibration zones under uncoupled charging conditions were analyzed according to the rock mass blast-weakening theory. The reasonable array pitch, length, and dip angle of boreholes were determined. The analysis on roof separation evaluated the displacement and loose 
circle of the surrounding rock in the gob-side entry and the stability and cementation status of surrounding rock in the 360,803 airway, hence providing a reference for studying the stability of surrounding rock in entries under similar conditions.

\section{Project Profile}

The \#8 coal seam was mined on the 360,805 working face through longwall mining on the strike, with a dip angle ranging from $2^{\circ}$ to $19^{\circ}$ (average dip angle of $5^{\circ}$ ) and thickness of 1.12-4.75 m (average coal thickness of $3.22 \mathrm{~m}$ ). The roof elevation of the 360,805 conveyor roadway ranged from $-707.39 \mathrm{~m}$ to $-741.81 \mathrm{~m}$, the recoverable strike length of this roadway was $900 \mathrm{~m}$, and the width of the working face was $220 \mathrm{~m}$. The immediate roof of the roadway was interbedded with sandstone and mudstone, with a thickness of 0.3-9.72 m (average thickness of $7.5 \mathrm{~m}$ ). Fractures were developed, which can easily lead to separation. The upper roof was composed of fine sandstone, with a thickness of 3.6-9.3 $\mathrm{m}$ (average thickness of $7.9 \mathrm{~m}$ ), and the roof was hard and not prone to caving. The layout plan is shown in Figure 1.

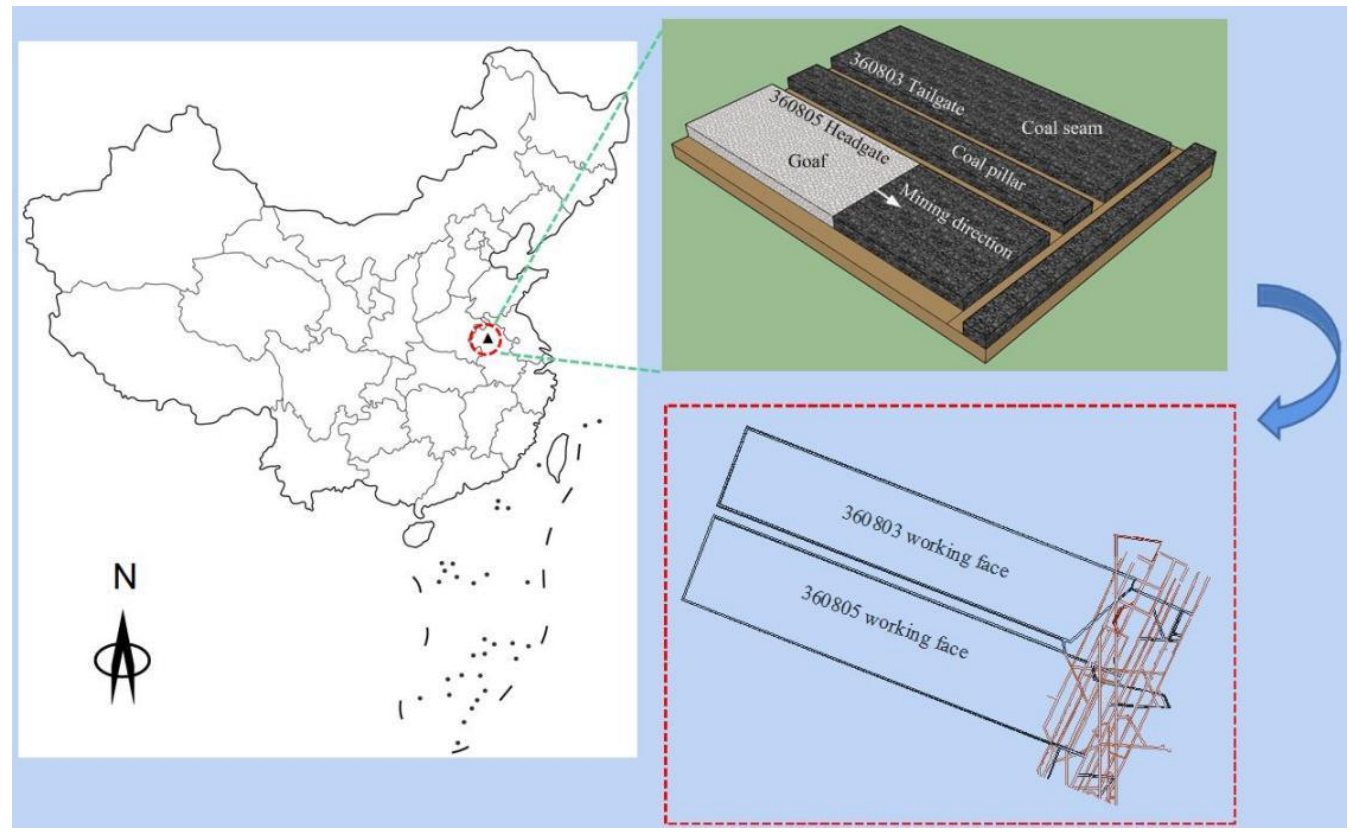

Figure 1. Plane position graph of 360,803 airway and 360,805 working face.

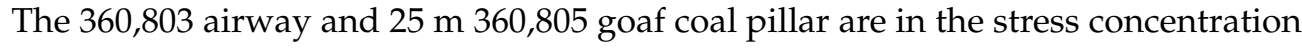
zone of goaf, with a high entry pressure. To mitigate the influence of dynamic mining pressure on the entry driving, directed presplitting blasting roof cutting is conducted in the 360,805 conveyor roadway to prevent roof caving during the mining process of the working face, thus relieving disturbances to the adjacent coal pillar roof and guaranteeing safe and reliable roadway roof support. The advanced roof-cutting pressure-relief roadway support technique that was applied during the mining process of the 360,805 working face was studied, and the stability and cementation status of the surrounding rock at the roof of the 360,803 airway under the mining influence were investigated.

\section{Construction of Mechanical Model}

As shown in Figure 2, $n_{r}$ is the number of fractured strata sequences in the roof; $n_{f}$ is the number of fractured rock strata sequences in the floor; $h_{r}$ stands for the fracture extension height in the roof $(\mathrm{m}) ; h_{f}$ is the fracture extension depth in the floor $(\mathrm{m}) ; X_{0}$ represents the width of the plastic zone at the lower wall of the 360,805 airway $(\mathrm{m}) ; X_{1}$ is the width of plastic zone at the upper wall of the 360,805 conveyor roadway $(\mathrm{m}) ; X_{3}$ is the width of plastic zone at the lower wall of the 360,803 airway $(\mathrm{m}) ; X_{2}$ represents the width 
of plastic zone of coal pillars (m); $A_{1}$ is the width of the 360,805 airway (m); $A_{2}$ is the width of the 360,805 conveyor roadway $(\mathrm{m}) ; l_{m}$ is the width of the 360,805 working face $(\mathrm{m})$; and $\alpha$ denotes the dip angle of the 360,805 working face $\left(^{\circ}\right)$.

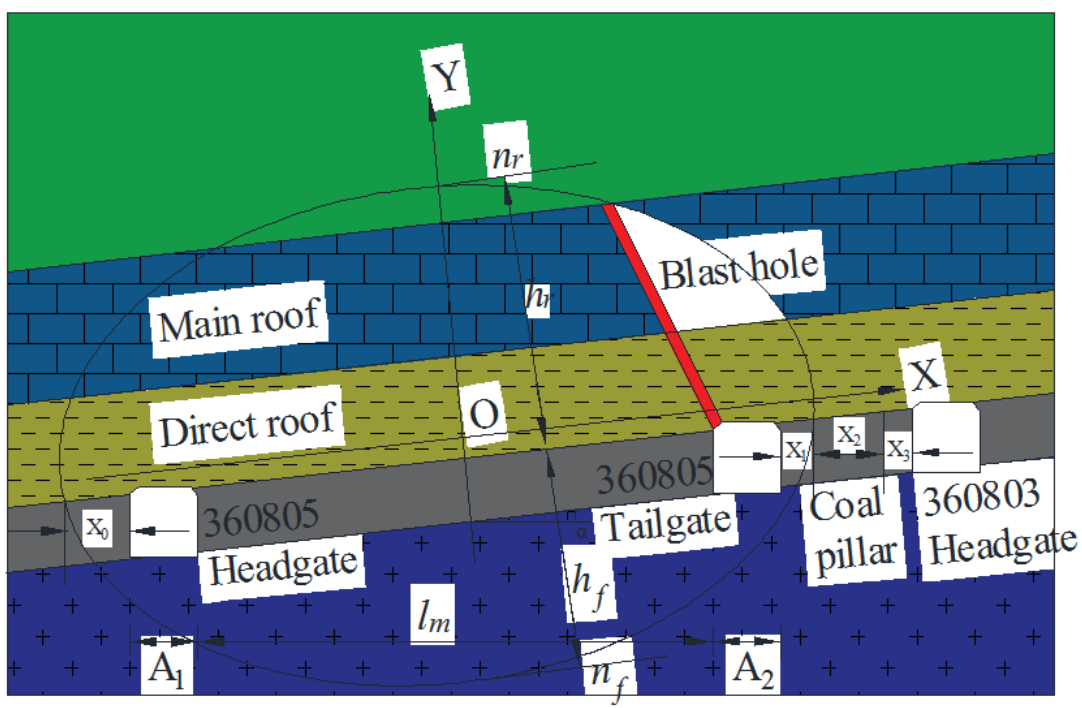

Figure 2. Dip section along the 360,805 working face.

Figure 3 illustrates that $N_{r}$ is the number of fractured strata sequences in the roof; $N_{f}$ is the number of fractured rock strata sequences in the floor; $H_{r}$ is the fracture extension height in the roof $(\mathrm{m}) ; H_{f}$ is the fracture extension depth in the floor $(\mathrm{m}) ; X_{0}$ represents the width of the plastic zone at the rear arch corner of the 360,805 working face $(\mathrm{m}) ; X_{1}$ is the width of the plastic zone at the rear arch corner of the 360,805 working face; and $L_{m}$ is the advancement length of the 360,805 working face $(\mathrm{m})$.

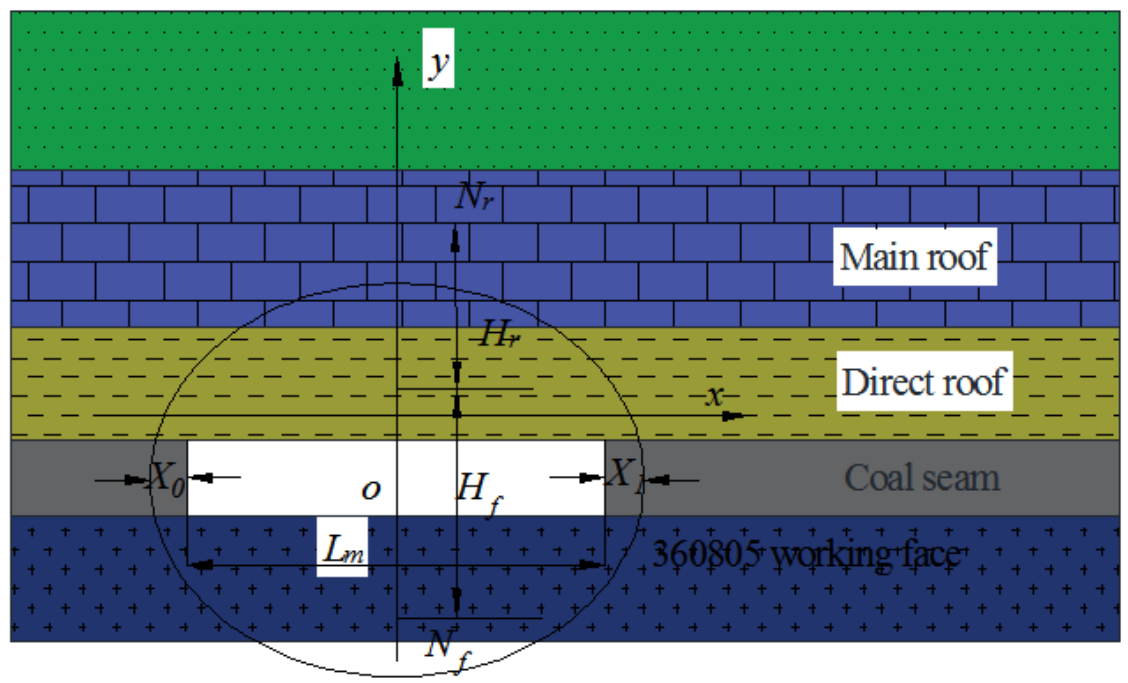

Figure 3. Strike section along 360,805 working face.

\section{Advanced Roof-Cutting Pressure-Relief Parameters of 360,805 Working Face and Process Study}

\subsection{Explosive Type}

Holes were drilled using a drilling rig with a diameter of $75 \mathrm{~mm}$. Deep hole blasting grains made of level III water-gel explosives that are allowed for use in coal mines were selected as explosives, with $0.3125 \mathrm{~kg} /$ cartridge. The explosives were detonated with an electric detonator used for coal mines. 


\subsection{Determination of Array Pitch of Boreholes}

\subsubsection{Radius of Crushed Zone}

A temperature as high as $1000{ }^{\circ} \mathrm{C}$ and a pressure as high as tens of thousands of $\mathrm{MPa}$ were generated upon the detonation of the explosives in the blast hole. The blasting shock wave was formed at a rate of thousands of meters per second. Under the action of shock wave and high-temperature and high-pressure blasting gas, high compressive stress was generated, which was much greater than the dynamic compressive strength of rocks. The surrounding rocks experienced crushing failure, and a crushed zone was formed.

The radius of the crushed zone is expressed as follows [22]:

$$
R_{c r z}=\left(\frac{\rho m c_{p}^{2}}{5 \sigma_{c}}\right)^{\frac{1}{2}} R_{c r l v}
$$

where

$$
c_{p}=\sqrt{\frac{E}{\rho_{m}}}
$$

In the above equation, $R_{c r z}$ is the radius of the crushed zone $(\mathrm{m}) ; R_{c r l v}$ is the limiting value of cavity radius $(\mathrm{m}) ; \sigma_{c}$ stands for the uniaxial compressive strength of rocks, taken as $128.0 \mathrm{MPa} ; \rho_{m}$ is the rock density at $2532 \mathrm{~kg} / \mathrm{m}^{3} ; c_{p}$ is the longitudinal wave velocity of rocks (m/s); and $E$ is the elasticity modulus of rocks at $37.15 \mathrm{GPa}$.

The cavity radius can be calculated through the following equation [22]:

$$
R_{c r l v}=\left(\frac{p_{w}}{\sigma_{0}}\right)^{\frac{1}{4}} r_{b}
$$

where

$$
\begin{gathered}
p_{w}=\frac{1}{8} \rho_{e} V_{d}^{2} \\
\sigma_{0}=\sigma_{c}\left(\frac{\rho_{m} c_{p}}{\sigma_{c}}\right)^{\frac{1}{4}}
\end{gathered}
$$

where $r_{b}$ denotes the radius of the borehole at $37.5 \mathrm{~mm} ; p_{w}$ is the average blasting pressure of explosives $(\mathrm{MPa}) ; \sigma_{0}$ is the rock strength under multidirectional stress conditions $(\mathrm{MPa}) ; \rho_{e}$ is the explosive density at $1.10 \times 103 \mathrm{~kg} / \mathrm{m}^{3}$; and $V_{d}$ is the detonation velocity of explosives at $3200 \mathrm{~m} / \mathrm{s}$.

$R_{c r z}$ is calculated as $0.6114 \mathrm{~m}$ according to the above equation.

The shock wave in the fractured zone attenuated rapidly; thus, the radius of the fractured zone was small. While the failure scope was not large, the degree of crushing was high, thus resulting in great energy consumption. The scope of the formed fractured zone should be reduced as much as possible during rock breaking through blasting.

\subsubsection{Radius of Fractured Zone}

Outside the fractured zone, the shock wave attenuated into compressive stress wave and continued radial propagation in rocks. The rocks simultaneously bore tangential tensile and radial compressive stresses, thus fracturing when the tangential tensile stress was greater than the tensile strength of rocks, and the radial fractures interlinked with the fractured zone were generated. The radial fractures continued to propagate and extend under the actions of high temperature, high pressure, expansion, extrusion, and air wedge of blasting gas. With the formation of the fractured zone, the radial fractures propagated and the blasting gas pressure in the blasting cavity declined to a certain extent. The elastic compressive deformation energy that originally accumulated in the rocks was released and converted into the unloading wave, which then propagated toward the center of the blasting source. Therefore, centripetal tensile stress wave contrary to the direction of 
compressive stress wave was generated. When the tensile stress value of the tensile stress wave was greater than the tensile strength of rocks, the rocks were fractured, thus forming annular fractures in the rocks around the blasting cavity. Given the staggered generation of radial and annular fractures, a fractured zone formed outside the crushing zone. The radial fractures played a dominant role in the fractured zone, and the advanced presplitting blasting failure on the working face mainly relied on the fractured zone.

As a result of the fast energy consumption during the shock wave propagation process, the peak stress was reduced. The attenuation law of the peak stress of the shock wave in the rocks with the propagation distance is expressed as follows [23]:

$$
p=\frac{p_{2}}{\bar{r}}
$$

where $p$ is the peak pressure of shock wave in rocks; $p_{2}$ denotes the initial shock pressure on the interface between explosives and exploded rocks; $\bar{r}$ is the contrast distance, $\bar{r}=r / r_{0} ; r_{0}$ is the radius of blasting cartridge or the radius of the blast hole under the blast hole charging mode; $r$ represents the distance from the point of shock wave pressure $p$ to the blasting center; and $\alpha$ is the pressure attenuation coefficient, which can be calculated through the following empirical formula:

$$
\alpha=2-\frac{v}{1-v}
$$

where $v$ is the Poisson's ratio at 0.31 .

The radius of the fractured zone can be solved through the following method:

(1) Calculation according to the action of blasting stress wave.

The peak tangential tensile stress $\sigma_{\theta \max }$ can be solved through the peak radial compressive stress $\sigma_{r \max }$, and the attenuation law of peak tangential tensile stress in rocks with distance, and $\sigma_{\theta \max }$ is obtained as follows [23]:

$$
\sigma_{\theta \max }=b \sigma_{r \max }=\frac{b p_{r}}{\overline{r^{a}}}
$$

where coefficient $b$ is correlated with the Poisson's ratio of rocks and stress propagation distance. The $b$ value in the zone close to blasting is large at $b \approx 1$, but the value declines rapidly with the increased distance and tends to just rely on the fixed value $b=v /(1-v)$ of Poisson's ratio. $p_{r}$ is the peak initial radial stress $(\mathrm{MPa})$.

Given that the radial fractures were caused by tensile stress, the peak tangential tensile stress $\sigma_{\theta \max }$ in the above equation was replaced by the tensile strength of rocks to solve the radius of radial fractured zone around the blast hole, as shown below.

$$
R_{p}=\left(\frac{b p r}{\sigma_{t}}\right)^{\frac{1}{a}} r_{b}
$$

where $R_{p}$ is the radius of the fractured zone $(\mathrm{m}) ; p_{r}$ represents the peak initial shock pressure on the hole wall $(\mathrm{MPa})$; and $\sigma_{t}$ stands for the tensile strength of rocks at $3.38 \mathrm{MPa}$.

Under the coupled charging mode [24],

$$
p_{r}=\frac{1}{4} \rho_{e} V_{d}^{2} \frac{2 \rho_{m} c_{p}}{\rho_{e} V_{d}+\rho_{m} c_{p}}
$$

Under the uncoupled charging mode [24],

$$
p_{r}=\frac{1}{8} \rho_{e} V_{d}^{2}\left(\frac{r_{c}}{r_{b}}\right)^{6} n
$$


where $r_{c}$ is the radius of the cartridge at $31.5 \mathrm{~mm}$; and $n$ is the stress increase amplitude generated by blasting gas colliding with the rock wall, which is generally taken as 8-11 and was set as 11 in this study.

The uncoupled charging mode was used for the roof presplitting blasting of the 360,805 working face. According to Equations (9)-(11), $R_{p}=2.6173 \mathrm{~m}$.

(2) Calculation according to the action of quasistatic pressure generated by blasting gas.

Following the shock wave, the blasting gas presented isentropic expansion in the blast hole, and the stress $p_{0}$ of blasting gas filling the blast hole [24] is

$$
p_{0}=\frac{1}{8} \rho_{e} V_{d}^{2}\left(\frac{d_{c}}{d_{b}}\right)^{6}
$$

where $d_{c}$ is the diameter of the cartridge at $63 \mathrm{~mm}$, and $d_{b}$ stands for the diameter of the borehole at $75 \mathrm{~mm}$.

The blasting gas sealed in the blast hole acted upon the blast hole wall in the form of quasistatic pressure to form a quasistatic stress field in rocks. The stress state was similar to a thick-walled cylinder (the outer diameter of cylinder was considered to tend to be infinitely great) that bore uniform internal pressure. Thus, the stress state in rocks can be solved using the theory of thick-walled cylinder in elastic mechanics, and its radial compressive stress was numerically equal to tangential tensile stress, namely,

$$
\sigma_{\theta}=\left|\sigma_{r}\right|=\left(\frac{r_{b}}{r}\right)^{2} p_{0}
$$

where $r$ is the distance from the blast hole center $(\mathrm{m}) ; \sigma_{r}$ denotes the radial compressive stress value (MPa); $\sigma_{\theta}$ is the tangential tensile stress value (MPa); and $p_{0}$ represents the stress of blasting gas filling the blast hole (MPa).

Similarly, the tangential tensile stress $\sigma_{\theta}$ in the above equation was replaced by the tensile strength $\sigma_{t}$ of rocks. To solve the radius of the fractured zone, the following equation is used:

$$
R_{p}=\left(\frac{p_{0}}{\sigma_{t}}\right)^{\frac{1}{2}} r_{b}
$$

where $p_{0}=0.49463 \mathrm{GPa}$ and $R_{p}=0.4536 \mathrm{~m}$, which were calculated from Equations (12)-(14).

The radius of the fractured zone was calculated according to the action of blasting stress wave and the quasistatic pressure of blasting gas. After blasting, the fractures around the blast hole were formed mainly due to the action of blasting stress wave, and the radius of the blast hole fractured zone was $R_{p}=2.6173 \mathrm{~m}$. The formed fractures were mutually penetrated after the adjacent blast holes in the roadway were successively detonated. Thus, the array pitch of boreholes was satisfied at $l_{j} \leq 2 R_{p}$. Therefore, $l_{j}=5.0 \mathrm{~m}$.

\subsubsection{Radius of Vibration Zone}

The stress wave was already considerably attenuated outside the fractured zone. When the stress value cannot cause rock failure but leads to the elastic vibration of rock mass point, a seismic wave was formed. The seismic wave can propagate to a far distance until the blasting energy is completely absorbed by rocks. The radius of the vibration zone can be estimated through the following equation:

$$
R_{s}=(1.5 \sim 2.8)^{3} \sqrt{Q}
$$

where $R_{S}$ is the radius of the vibration zone $(\mathrm{m})$, and $Q$ is the explosive payload needed by simultaneous detonation at $26.25 \mathrm{~kg}$.

The radius $R_{S}$ of the vibration zone was calculated as $4.4579-8.3215 \mathrm{~m}$. Reinforced support was realized using a lifted monomer shed along the strike within the vibration zone, as shown in Figure 4. 


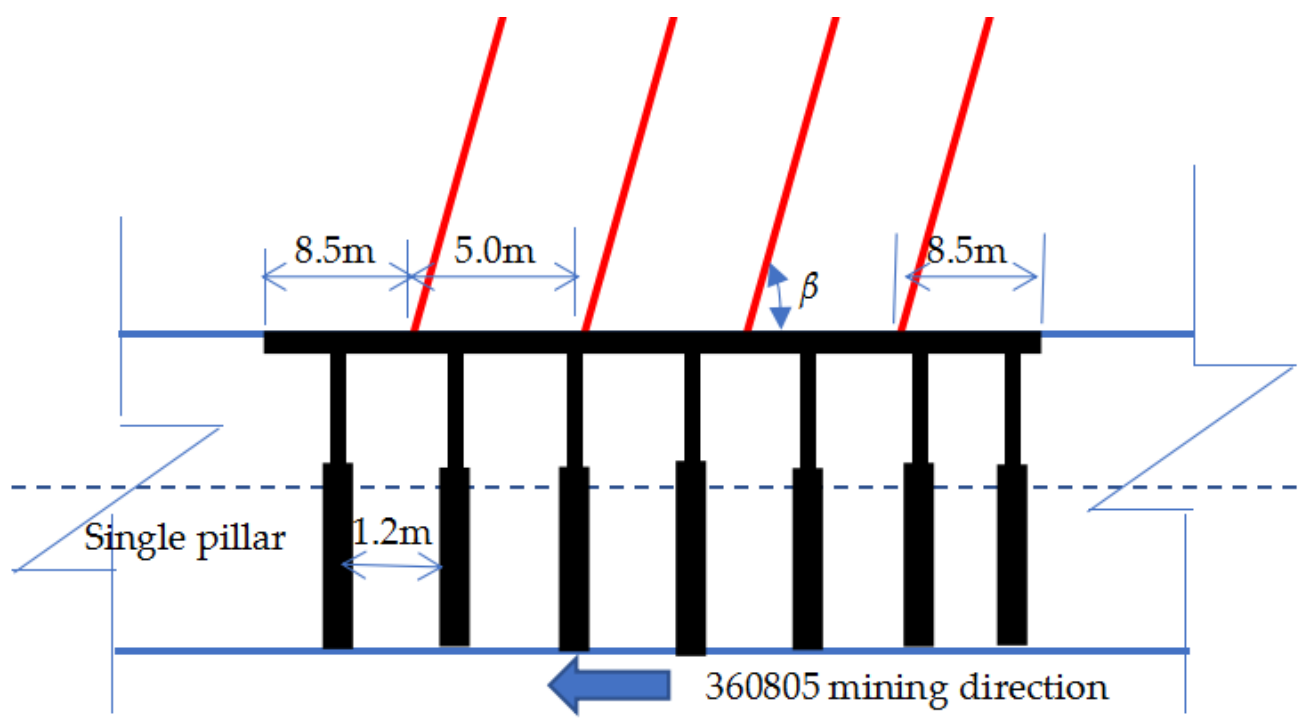

Figure 4. Scope of reinforced support in the vibration zone.

\subsection{Roof-Cutting Height}

\subsubsection{Stratum Judgment of Hard Roof Strata}

The mechanical parameters of roof strata in the conveyor roadway of the 360,805 working face are shown in Table 1. According to the principle of composite beam, the load $q(i, j)$ applied by the stratum $j$ to the stratum $i$ in the roof is obtained as [25]

$$
q(i, j)=E_{i} h_{i}^{3} \sum_{t=i}^{j} h_{t} \gamma_{t} / \sum_{t=i}^{j} E_{t} h_{t}^{3}
$$

where $i, j$, and $t$ are the serial numbers of roof strata sequences; the rock strata are numbered from bottom to top; $n_{r} \geq j \geq i ; n_{r}$ is the number of strata sequences at the apex of arch; and $E_{i}, h_{i}$, and $y_{i}$ represent the elasticity modulus (MPa), stratum thickness $(\mathrm{m})$, and unit weight $\left(\mathrm{kN} / \mathrm{m}^{3}\right)$ of roof at the stratum $i$, respectively.

Table 1. Mechanical parameters of roof strata in the conveyor roadway of the 360,805 working face.

\begin{tabular}{cccccccc}
\hline NO. & Lithology & $\begin{array}{c}\text { Thickness } \\
(\mathbf{m})\end{array}$ & $\begin{array}{c}\text { Elastic } \\
\text { Modulus } \\
\text { E/(GPa) }\end{array}$ & $\begin{array}{c}\text { Tensile } \\
\text { Strength } \\
\sigma_{t}(\mathbf{M P a})\end{array}$ & $\begin{array}{c}\text { Compressive } \\
\text { Strength } \\
\sigma_{\boldsymbol{c}}(\mathbf{M P a})\end{array}$ & $\begin{array}{c}\text { Density } \\
\boldsymbol{\rho}\left(\mathbf{/ k g} \cdot \mathbf{m}^{-3}\right)\end{array}$ & $\begin{array}{c}\text { Coefficient } \\
\text { of Dilatancy }\end{array}$ \\
\hline 11 & Sandy mudstone & 16.95 & 21.04 & 2.96 & 58.72 & 2507 & 1.15 \\
10 & Mudstone & 2.80 & 12.35 & 2.17 & 36.27 & 2461 & 1.20 \\
9 & Quartz sandstone & 7.65 & 35.72 & 8.91 & 158.7 & 2684 & 1.15 \\
8 & Fine sandstone & 5.06 & 30.45 & 5.85 & 89.07 & 2596 & 1.15 \\
7 & Mudstone & 2.12 & 13.59 & 1.86 & 30.17 & 2448 & 1.20 \\
6 & \#9 coal seam & 0.62 & $/$ & $/$ & $/$ & $/$ & 1.25 \\
5 & Mudstone & 0.41 & 11.84 & 1.28 & 32.15 & 2463 & 1.20 \\
4 & \#9 lower coal seam & 0.55 & $/$ & $/$ & $/$ & $/$ & 1.25 \\
3 & Mudstone & 0.98 & 14.15 & 1.58 & 34.86 & 2485 & 1.20 \\
2 & Fine sandstone & 9.32 & 37.15 & 3.38 & 128.0 & 2532 & 1.15 \\
1 & Mudstone & 4.50 & 12.15 & 2.04 & 43.12 & 2417 & 1.20 \\
0 & 8\# coal seam & 3.22 & $/$ & $/$ & $/$ & $/$ & 1.25 \\
\hline
\end{tabular}

According to the above equation, from the first stratum $(i=1)$ of the roof, if $q(I,(j+1))$ $\leq q(i, j)$, then the stratum $j+1$ is the first hard rock stratum, and the judgment was made continuously upward from the stratum $j+1$. 


\subsubsection{Strata Load at Hard Roof Strata}

The strata load borne by the hard roof strata before the fracture was the self-weight load of hard strata and soft strata they controlled. When $k<k_{r}$, the strata load borne by the hard roof stratum $k$ was calculated through Equation (16)

$$
q_{k}=q\left(Y_{k},\left(Y_{k+1}-1\right)\right)
$$

where $k$ is the serial number of the hard rock stratum in the roof and floor; $k_{r}$ represents the total number of hard roof strata within the elliptic stress arch; $Y_{k}, Y_{k+1}$, and $Y_{k r}$ denote the numbers of sequences of the $k(\mathrm{th}), k+1(\mathrm{th})$, and top hard rock strata, respectively; and $Y_{k+1}-1$ stands for the number of sequences of the top soft rock stratum controlled by the $k$ (th) hard roof stratum.

When $k=k_{r}$, the strata load borne by the top hard roof stratum is

$$
q_{k r}=q\left(Y_{k r}, n\right)
$$

where $n$ is the number of roof strata sequences.

\subsubsection{Breaking Span of Hard Roof Strata and Their Fracturing Order}

The breaking span [25] $l_{k}$ of the hard roof strata presenting a cantilever beam state is

$$
l_{k}=H_{k} \sqrt{\frac{R_{k}}{3 q k}}
$$

where $H_{k}$ and $R_{k}$ are the thickness $(\mathrm{m})$ and tensile strength $(\mathrm{MPa})$ of the $k($ th) hard roof and floor stratum, respectively.

The fracturing order of hard roof strata was determined from the bottom to the apex of the arch. If $l_{k+1}>l_{k}$, then the $k($ th) hard stratum was fractured first, followed by the $k+1$ (th) hard stratum.

If $l_{k+1} \leq l_{k}$, then the $k+1$ (th) and $k$ (th) hard strata were combined with the controlled soft strata, thus forming a layer of composite beam. If $k+1<k_{r}$, then $q_{k}=q\left(Y_{k},\left(Y_{k+2}-1\right)\right.$; if $k+1=k_{r}, q_{k}=q\left(Y_{k}, n_{r}\right)$, then the breaking span $l_{k}$ of the $k($ th $)$ hard stratum was recalculated. Thus, the breaking span of hard roof strata and their fracturing order were determined. $Y_{k+2}-1$ denotes the number of sequences at the top soft stratum controlled by the $k+1($ th) hard roof stratum.

\subsubsection{Number of Roof Strata Sequences $\left(Y_{\mathrm{cm}}\right)$ Filling the Goaf}

A hinged structure can be easily formed after the hard roof strata in the goaf were fractured, while the soft strata acted upon the hard strata in the form of load. The rock strata were numbered from the bottom upwards from the first roof stratum, and the number of roof strata sequences $\left(Y_{c m}\right)$ in the goaf was determined through the following equation [26]:

$$
h_{m c}-\left(h_{m c}(1-\eta) P_{0}+\sum_{i=1}^{Y_{c m}} h_{i}\left(P_{i}-1\right)\right)=0
$$

where $h_{m c}$ is the mining height of the working face $(\mathrm{m}) ; \eta$ denotes the recovery ratio of the working face; $P_{0}$ and $P_{i}$ are the broken expansion coefficients of coal seam and the $i$ (th) roof stratum, respectively; $i$ stands for the sequence number of roof strata; and $Y_{c m}$ is the number of roof strata sequences filling the goaf.

If a key stratum existed within the caving zone, then the overlying strata in a certain range caved in case of fracture of the key stratum, resulting in violent weighting on the working face and triggering support crushing accident. The key stratum must be weakened by taking artificial presplitting blasting measures until it moves upward beyond the caving zone, thus mitigating the risk of overall strata fracture. 
According to Equation (18), the strata loads borne by three hard strata within the range of 11 rock strata in the roof of the $\# 8$ coal seam were calculated as $q_{1}=0.40529 \mathrm{MPa}$, $q_{2}=0.26427$, and $q_{3}=0.41644$.

Through Equation (19), the weighting steps of the three hard strata were calculated as $l_{1}=15.5392 \mathrm{~m}, l_{2}=25.6458 \mathrm{~m}$, and $l_{3}=26.0903 \mathrm{~m}$.

Given the calculation, the fine sandstone at the second stratum, quartz sandstone at the ninth stratum, and sandy mudstone at the 11th stratum within the range of 11 rock strata in the roof of the \#8 coal seam were hard strata. $Y_{c m}=6$ was calculated by using Equation (20), namely, after the \#8 coal seam was mined and caved to the $9 \#$ coal seam at the sixth stratum and the goaf was filled with gangues. Therefore, the roof-cutting height was designed as $H_{d}=13.8 \mathrm{~m}$.

\subsection{Depth of Blast Hole $P_{l}$}

The blast hole depth was determined according to the roof-cutting height and dip angle of the borehole, as shown in Figure 5. The dip angle of the borehole was taken as $\alpha=60^{\circ}$, and the deviation angle of the borehole toward the 360,805 goaf was $\beta=80^{\circ}$. Thus, the depth of the blast hole is

$$
P_{l}=\frac{H_{d}}{\sin \alpha \sin \beta}
$$

$P_{l}=16.0 \mathrm{~m}$ was calculated.

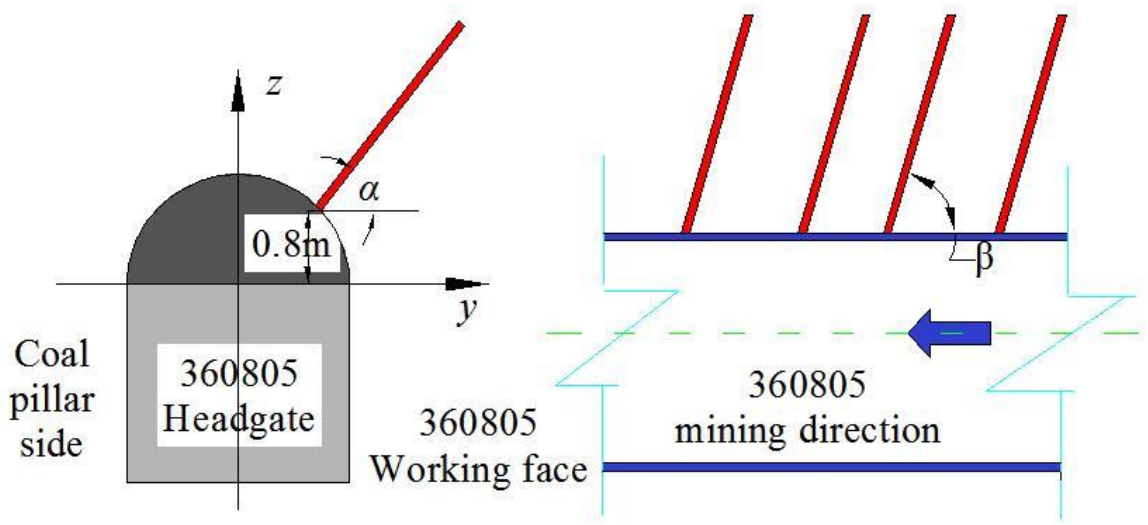

Figure 5. Borehole layout.

\subsection{Charging Structure}

The blast hole was sealed using yellow mud, and the sealing length was not greater than $5.5 \mathrm{~m}$. To ensure the safe detonation of the blasting network, two detonators were installed in the same segment of each blast hole, and a series blasting network was used, as shown in Figure 6.

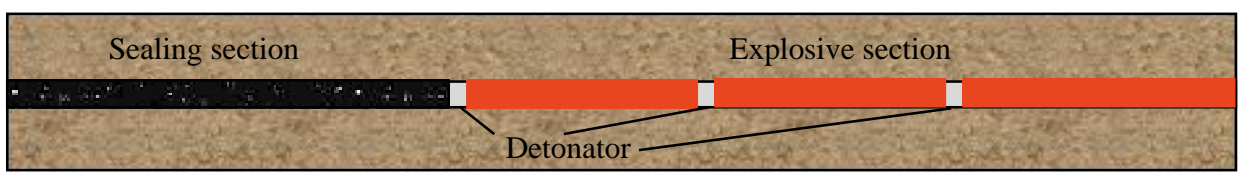

Figure 6. Charging structure.

The forced caving blasting process is described as follows: Hole drilling $\rightarrow$ hole exploration $\rightarrow$ perforation $\rightarrow$ detonator conduction $\rightarrow$ fabrication of cannon head $\rightarrow$ charging $\rightarrow$ hole sealing $\rightarrow$ conductivity inspection $\rightarrow$ alarming and evacuation $\rightarrow$ wire connection $\rightarrow$ inform coal mine dispatcher of blasting $\rightarrow$ post-blasting inspection $\rightarrow$ disarming. 


\section{Stability Judgment of Roadway-Supporting Coal Pillars in Roof-Cutting Pressure-Relief Roadway under Mining Influence \\ 5.1. Strata Load Borne by Coal Pillars}

After the working face was mined, the overlying strata load was transferred to the goaf boundary. If the mining height was great or the roof was hard and had difficulty caving, and the caving gangues did not fill the goaf without any supporting effect on the overlying strata, then the hanging roof length in the goaf and the strata load borne by the coal pillars were great. If the mining height was small or the roof could be easily caved, and the caving gangues filled the goaf, exerting a supporting effect on the overlying strata, then the hanging roof length in the goaf was short and the strata load borne by the coal pillars was small [27].

Therefore, the strata load borne by the coal pillars was correlated with goaf filling degree, hanging roof length in the goaf, mining depth, mining height, and overlying strata structure.

\subsection{Number of Sequences $\left(Y_{j x}\right)$ at Roof Caving Limit Stratum}

The stratum that stopped upward caving in the goaf was defined as the roof caving limit stratum. If the short-edge length $D_{k}$ of suspending hard roof strata was not smaller than their breaking span $l_{k}$ and the number of sequences $\left(Y_{j x}\right)$ at the roof caving limit stratum was smaller than $Y_{c m}$, then the suspending hard roof strata experienced fracturing. The following is obtained [26]:

$$
\left\{\begin{array}{c}
D_{k} \geq l_{k} \\
Y_{j x}<Y_{c m}
\end{array} \quad\left(k=1,2 \ldots K_{t}\right)\right.
$$

where $D_{k}=D_{0}-2 \sum_{i=1}^{Y_{k}-1} h_{i} \cot \delta_{i}$

The rock strata continued upward caving; otherwise, the upward caving was stopped. According to Equation (11), the number of sequences $\left(Y_{j x}\right)$ at the roof caving limit stratum can be solved.

Where $K_{t}$ is the number of hard strata caving within $Y_{c m}$. When $K_{t}<K_{y}, Y_{j x}=Y_{k+1}-1$; when $K_{t}=K_{y}, Y_{j x}=Y_{c m} ; D_{k}$ denotes the short-edge length of suspending hard roof strata (m); $D_{0}$ represents the length of the adjacent goaf $(\mathrm{m}) ; Y_{k-1}$ and $Y_{k+1}-1$ represent the number of sequences at the top soft strata controlled by the $k-1$ (th) and $k$ (th) hard strata, respectively; and $\delta_{i}$ is the breaking angle of the $i\left(\right.$ th) roof stratum $\left(^{\circ}\right)$.

\subsection{Hanging Roof Length L in the Goaf}

If $Y_{j x}<Y_{c m}$, then the caving gauges did not fill the goaf. Hence, the caving strata had no supporting effect on the overlying strata. Thus, $L=D_{0}$, as shown in Figure 7.

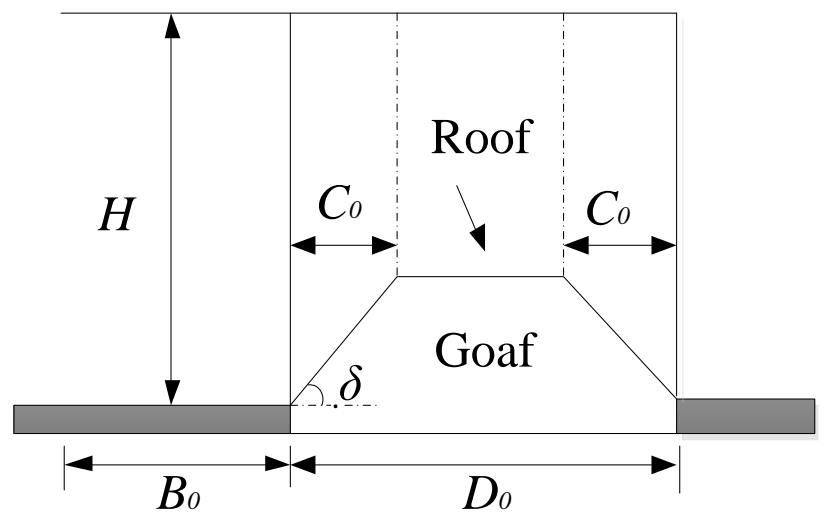

Figure 7. Loading diagram of coal pillar. 
If $Y_{j x}=Y_{c m}$, then the caving gauges filled the goaf. Hence, the caving strata exerted a supporting effect on the overlying strata. Thus, $L=C_{0}$, namely,

$$
L=\left\{\begin{array}{cc}
D_{0} & Y_{j x}<Y_{c m} \\
C_{0} & Y_{j x}=Y_{c m}
\end{array}\right.
$$

where $C_{0}=\sum_{i=1}^{Y_{j x}} h_{i} \cot \delta_{i}$, which is the residual roof length at the goaf boundary $(\mathrm{m})$

\subsection{Critical Coal Pillar Width $B_{0}$}

If the stress transfer to the deep part of coal pillars is induced by the failure of coal pillar edge, then the average stress $\sigma_{a}$ on the coal pillars is as follows:

$$
\sigma_{a}=\frac{1}{B_{0}}\left(\left(B_{0}+\frac{L}{2}\right) \gamma H-\frac{N_{0}}{2}\right)
$$

where $N_{0}=\left\{\begin{array}{ll}\frac{\gamma\left(D_{0}-C_{0}\right) C_{0}}{\cot \delta} & L=D_{0} \\ \frac{\gamma C_{0}^{2}}{2 \cot \delta} & L=C_{0}\end{array} \quad\right.$, where $N_{0}$ represents the dead weight of caving strata in the goaf $(\mathrm{kN}) ; H$ denotes mining depth $(\mathrm{m}) ; \delta$ is the average caving angle of strata within $Y_{j x}\left({ }^{\circ}\right), \delta=\frac{1}{Y_{j x}} \sum_{i=1}^{Y_{j x}} \delta_{i}$; and $\gamma$ is the average unit weight of overlying strata $\left(\mathrm{kN} / \mathrm{m}^{3}\right)$.

The following can be acquired according to the empirical strength formula of coal pillar proposed by Obert-Duvall/Wang.

$$
R=R_{u c}\left(0.778+0.222 \frac{B_{0}}{h}\right)
$$

where $R$ is the strength of the coal pillar $(\mathrm{MPa}) ; R_{u c}$ stands for the uniaxial compressive strength of the coal seam (MPa); and $h$ is the height of the coal pillar (m), which is the mining height of the adjacent working face, namely, $h=h_{m c}$.

$\sigma=R$ is set according to Equations (24) and (25). Thus, the critical coal pillar width is obtained as follows:

$$
B_{0}=\frac{-0.778 R_{c}+\gamma H+\sqrt{\left(0.778 R_{c}-\gamma H\right)^{2}-0.444 \frac{R_{c}}{h_{m c}}\left(N_{0}-\gamma L H\right)}}{0.444 \frac{R_{c}}{h_{m c}}}
$$

The critical coal pillar width $B_{0}$ is related to the hanging roof length $L$ in the goaf, mining depth $H$, mining height $h_{m c}$, and compressive strength of coal seam $R_{c}$.

In the above equation, the parameters were taken as $R_{c}=9.8 \mathrm{MPa}, \gamma=24 \mathrm{kN} / \mathrm{m}^{3}$, $H=740 \mathrm{~m}, h_{m c}=3.22 \mathrm{~m}$. Calculations indicate that $L=4.172 \mathrm{~m}$ and $B_{0}=17.9961 \mathrm{~m}$. Thus, $25 \mathrm{~m}$ coal pillars were reserved with a safety factor of 1.3852, which satisfied the safety requirements.

\section{Investigation on Stability and Cementation of Surrounding Rock}

Drilling construction was conducted $400 \mathrm{~m}$ away from the gate by using a drilling peep to observe the roof separation cracks of the goaf adjacent to the 360,805 machine roadway, as shown in Figure 8. The advanced roof-cutting pressure-relief blasting effect of the 360,805 conveyor roadway was evaluated and analyzed to alleviate the disturbance caused by the 360,805 goaf to the roof of the adjacent 360,803 airway. Figure 8 shows that the roof condition is less damaged at a depth of about $6 \mathrm{~m}$. When the depth is about $8 \mathrm{~m}$, the surrounding rock damage degree is large possibly because of the drilling process. On the whole, the surrounding rock in the deep part of the roof has good stability. 


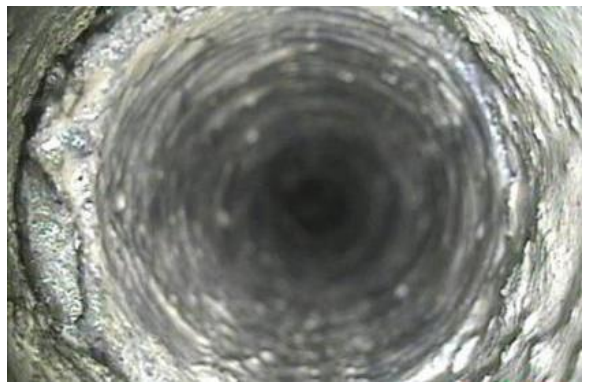

(a) $6.839 \mathrm{~m}$

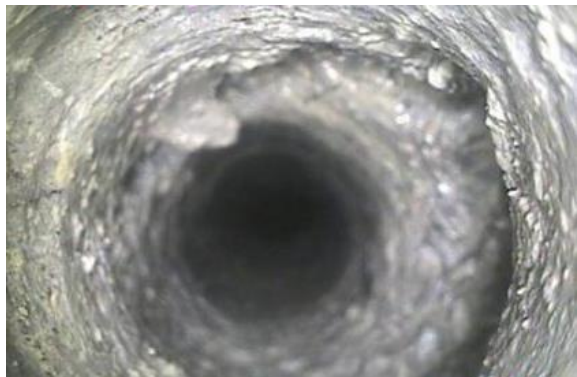

(c) $8.597 \mathrm{~m}$

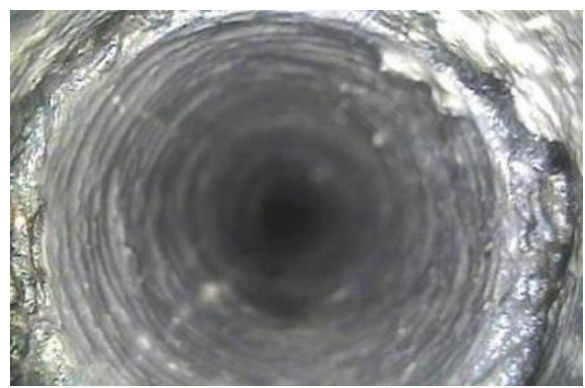

(b) $8.155 \mathrm{~m}$

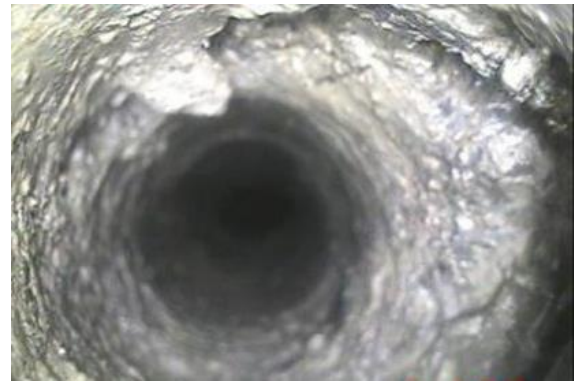

(d) $8.623 \mathrm{~m}$

Figure 8. Borehole views at the roof of the 360,805 conveyor roadway.

The displacement of surrounding rock in the 360,803 airway was continuously monitored using a roof separation instrument. Figure 9 shows the roof separation and deformation characteristics of surrounding rock in the 360,803 airway.

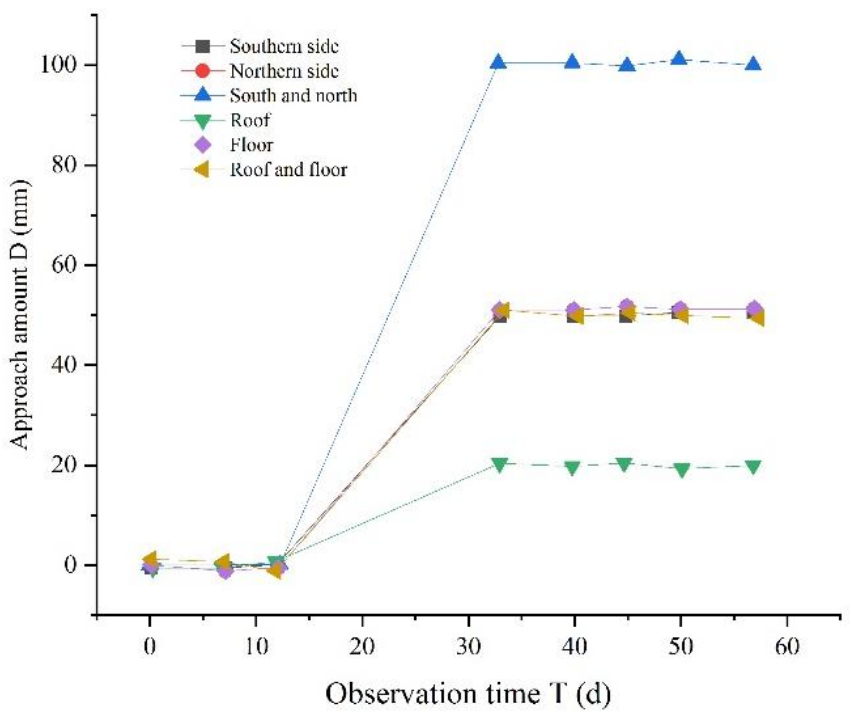

Figure 9. Displacement observation of surrounding rock in the 360,803 airway.

Figure 9 shows that the two sides of the roadway surrounding rock move the most, reaching about $100 \mathrm{~mm}$, and the bottom heave is also relatively large at about $60 \mathrm{~mm}$ with roof subsidence of about $20 \mathrm{~mm}$.

The 360,803 air roadway adopts anchor mesh cable support, and the support parameters are as follows: The anchor bolt is a $\varphi 22 \mathrm{~mm} \times 2500 \mathrm{~mm}$ left-handed metal strong bolt, the row spacing between roof bolts is $800 \times 800 \mathrm{~mm}$, the row spacing between side anchors of the three-core arch section is $850 \times 800 \mathrm{~mm}$, the row spacing between the side anchors of the flat-top section is $800 \times 800 \mathrm{~mm}$; and the anchor cable is a $\varphi 21.8 \mathrm{~mm} \times 7200 \mathrm{~mm}$ 
prestressed steel strand anchor cable with row spacing of $1200 \times 1600 \mathrm{~mm}$ and four pieces in each row, and $\varphi$ is the bolt (anchor cable) diameter, as shown in Figure 10.

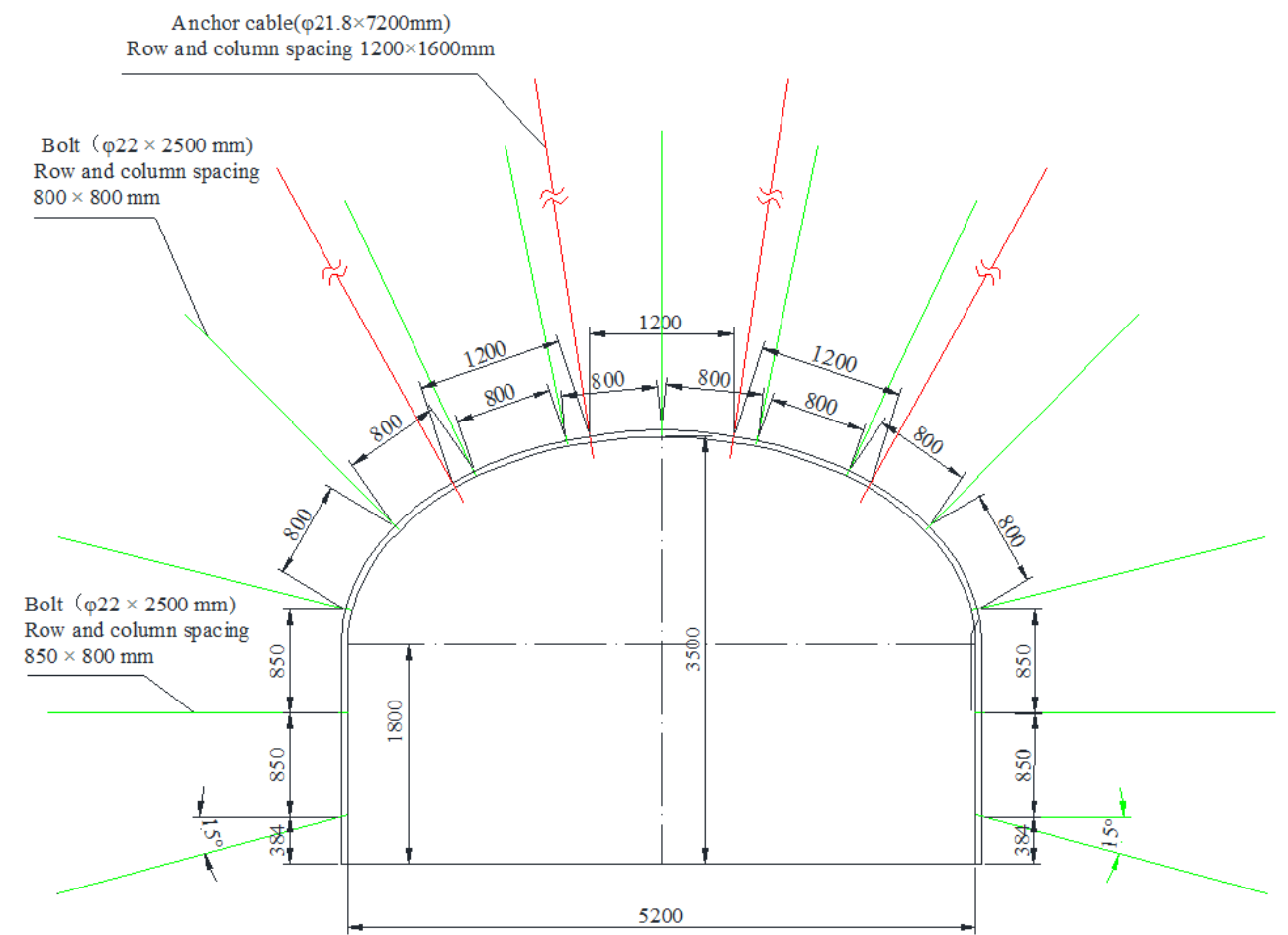

Figure 10. Roadway support design.

The stress borne by the anchor bolt (cable) in the 260,805 conveyor roadway was tested using ergometers, as shown in Figures 11-13.

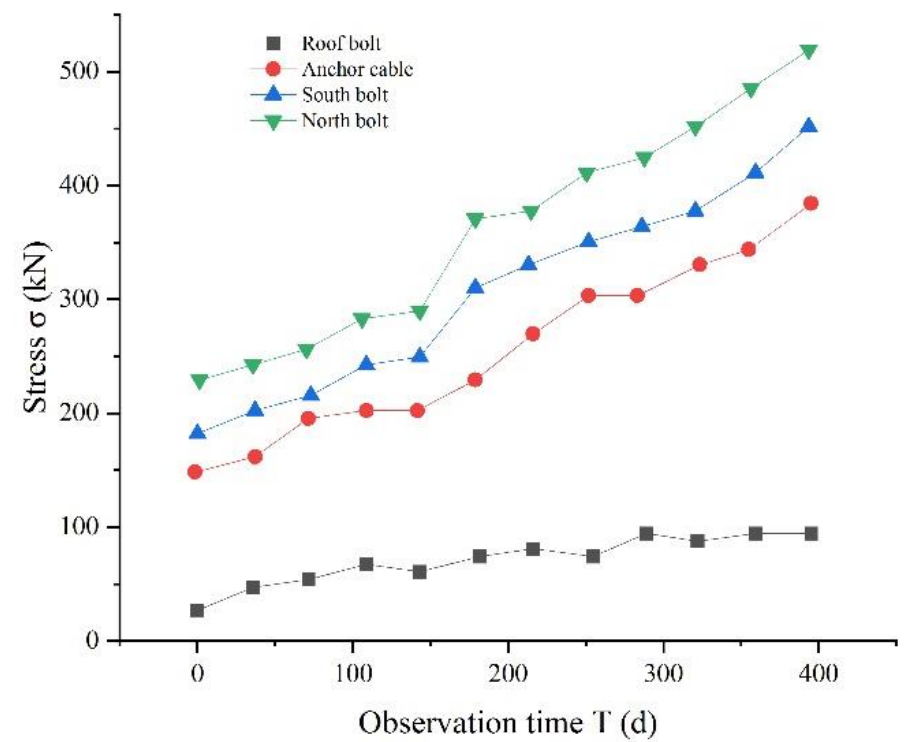

Figure 11. Variation trend of the stress borne by the anchor bolt (cable) in the second group of ergometers in the conveyor roadway of the 360,805 working face. 


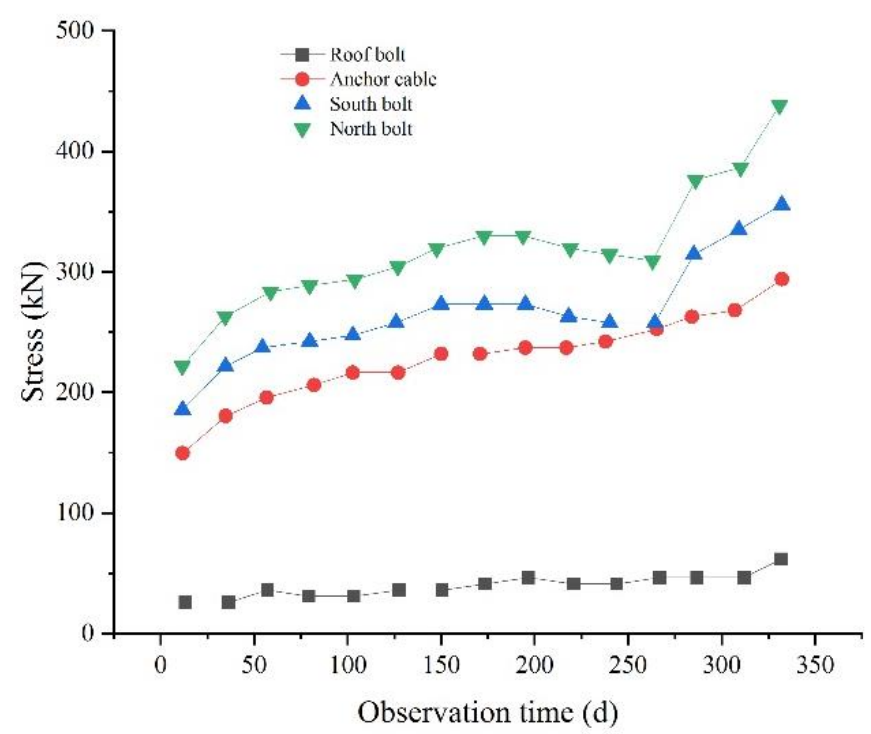

Figure 12. Variation trend of the stress borne by the anchor bolt (cable) in the second group of ergometers in the conveyor roadway of the 360,805 working face.

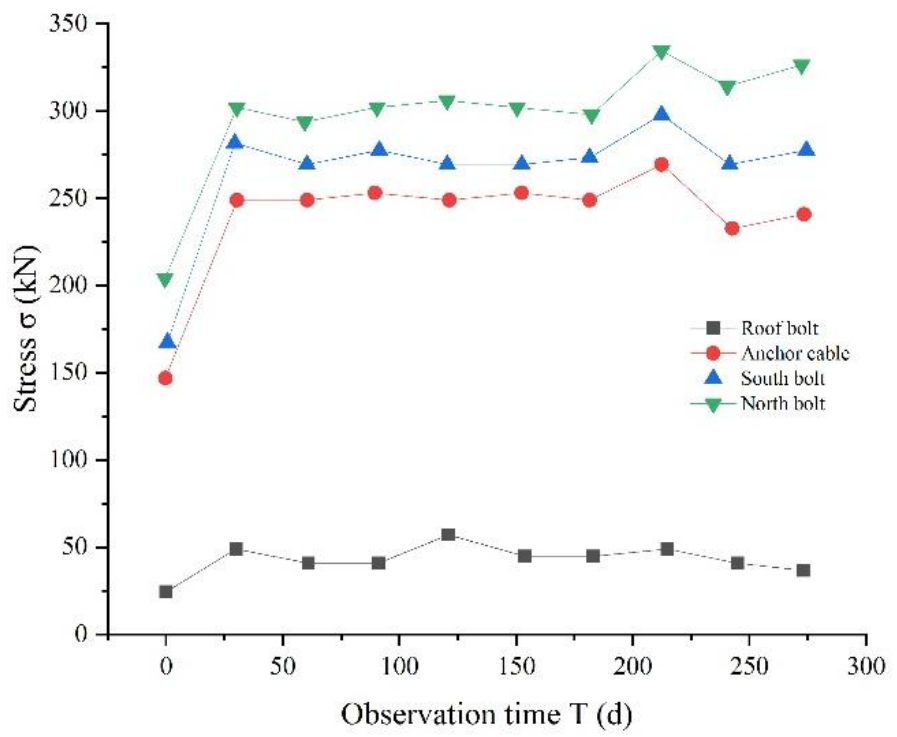

Figure 13. Variation trend of the stress borne by the anchor bolt (cable) in the third group of ergometers in the conveyor roadway of the 360,805 working face.

Figures 11-13 show the stress of the anchor bolt (cable) of the surrounding rock of the 360,803 air roadway during the monitoring process. The stress change of the anchor bolt (cable) can directly reflect the deformation of the surrounding rock of the roadway. Figures 11-13 indicate that the stress of the two sides of anchor bolts (cables) is relatively large, followed by the stress of the roof anchor cable, with the stress of the roof anchor bolt being the smallest. This finding shows that during the use of the roadway, the anchor cable of the roof plays a greater role in supporting the deformation of the roof after the roof is damaged. The anchor bolt of the roof is in the crushing area and bears less interaction force than the anchor cable. The role of the anchor bolt is mainly to control the displacement of the broken rock of the roof and to maintain the overall stability of the roof. The deformation of the surrounding rock of the two sides is mainly supported by the anchor bolts of the two sides.

Drilling construction was conducted $400 \mathrm{~m}$ from the gate, and the surrounding rock loose circle in the 360,803 airway was tested using a geological radar, as shown in Figure 14. 
The floor was $2.5-3.8 \mathrm{~m}$ (mean value of $3.2 \mathrm{~m}$ ), the north wall was $1.3-1.8 \mathrm{~m}$ (mean value of $1.5 \mathrm{~m}$ ), the roof was $1.1-1.9 \mathrm{~m}$ (mean value of $1.5 \mathrm{~m}$ ), and the south wall was $1.1-1.5 \mathrm{~m}$ (mean value: $1.4 \mathrm{~m}$ ).

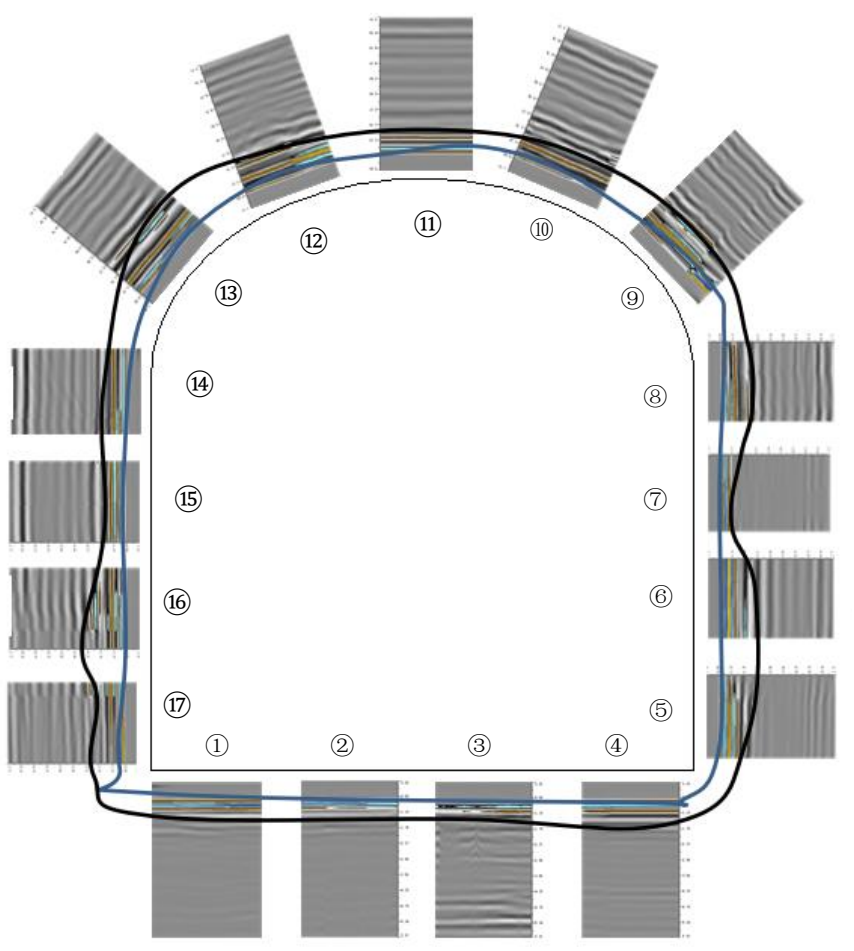

Figure 14. Scanning graph of surrounding rock loose circle in the 360,803 airway.

On the basis of the roof separation fracture and the displacement of surrounding rock and surrounding rock loose circle in the roadway close to the goaf, the surrounding rock in the 360,803 airway showed good stability and cementation status, thus ensuring the safety of roadway excavation.

\section{Conclusions}

(1) The radiuses of crushed, fractured, and vibration zones under the uncoupled charging condition were calculated as $R_{p}=2.617 \mathrm{~m}, R_{c}=0.611 \mathrm{~m}$, and $R_{s}=4.458-8.322 \mathrm{~m}$, respectively. The array pitch of boreholes was determined as $l_{j}=5.0 \mathrm{~m}$, and the scope of reinforced support in the blasting process was $8.5 \mathrm{~m}$ before and after the blast hole.

(2) A mechanical model of the overlying roof strata structure on the working face was constructed using the theory of mine pressure to explore the migration laws of roof strata and calculate the horizon, breaking span, and caving order of hard roof strata. Hence, the fine, quartz, and sandy sandstones at the second, ninth, and 11th strata among 11 rock strata in the \#8 coal seam were assumed to be hard strata. After the \#8 coal seam was mined and caved to the \#9 coal seam at the sixth stratum, the goaf was filled with gangues. Thus, the roof-cutting height of the roadway was determined as $H_{d}=13.8 \mathrm{~m}$.

(3) On the basis of the theory of key stratum, the number of sequences at the roof caving limit stratum and hanging roof length in the goaf were $Y_{j x}=6 \mathrm{~m}$ and $L=4.17 \mathrm{~m}$, respectively. The critical coal pillar width was $B_{0}=17.996 \mathrm{~m}$, and $25 \mathrm{~m}$ coal pillars were reserved with the safety factor of 1.385 , hence meeting the safety requirements.

(4) The stability and cementation status of surrounding rock in the 360,803 airway were evaluated and analyzed based on the roof separation fracture and displacement of surrounding rock and surrounding rock loose circle in the roadway close to the goaf. The roadway roof is separated at about $8 \mathrm{~m}$, and the roof subsidence is the smallest. The two 
sides move the most, followed by the bottom heave. This finding is mutually confirmed by the stress of the anchor bolt (cable), thus ensuring the safety of roadway excavation.

Author Contributions: Methodology, X.Y., M.T. and Y.L.; data curation, X.Y., Y.L., G.C. and C.L.; formal analysis, X.Y., M.T., Y.L., G.C. and C.L.; investigation, X.Y., G.C. and C.L.; project administration, M.T. and Y.L.; software, Y.L.; writing — original draft preparation, X.Y., Y.L. and G.C.; writing - review and editing, Y.L., G.C. and C.L.; funding acquisition, M.T. and Y.L. All authors have read and agreed to the published version of the manuscript.

Funding: The work was supported by the National Natural Science Foundation of China (Nos. 51574226, 51574005, 51774010).

Institutional Review Board Statement: Not applicable.

Informed Consent Statement: Not applicable.

Data Availability Statement: Data are contained within the article.

Conflicts of Interest: The authors declare no conflict of interest.

\section{References}

1. Hua, X.Z.; Yang, P. Floor deformation dynamic evolution of gob-side entry retaining with large section in deep mine. J. China Univ. Min. Technol. 2018, 47, 494-501.

2. Zhang, N.; Chen, H.; Chen, Y. An engineering case of gob-side entry retaining in one kilometer-depth soft rock roadway with high ground pressure. J. China Coal Soc. 2015, 40, 494-501.

3. Yang, P.; Hua, X.Z.; Yang, K.; Pang, D.D.; Cheng, S.X. Experiment of compound roof deformation characteristics of gob-side retaining entry in deep mine and support measures. J. Min. Saf. Eng. 2017, 34, 1067-1074.

4. Zhang, G.F.; He, M.C.; Yu, X.P.; Huang, Z.G. Research on the Technique of No-Pillar Mining with Gob-Side Entry Formed by Advanced Roof Caving in the Protecticve Seamin Bai jiao Coal Mine. J. Min. Saf. Eng. 2011, 28, 511-516.

5. He, M.C.; Chen, S.Y.; Guo, Z.B.; Yang, J.; Gao, Y.B. Control of surrounding rock structure for gob-side entry retaining by cutting roof to release pressure and its engineering application. J. China Univ. Min. Technol. 2017, 46, 959-969.

6. He, M.C.; Ma, X.G.; Niu, F.L.; Wang, J.; Liu, Y.X. Adaptability research and application of rapid gob-side entry retaining formed by roof cutting and pressure releasing with composite roof and medium thick coal seam. Chin. J. Rock Mech. Eng. 2018, 37, 2641-2654.

7. Hua, X.Z.; Liu, X.; Huang, Z.G.; Yang, P.; Ma, Y. Stability mechanism of non-pillar gob-side entry retaining by roof cutting under the coupled static-dynamic loading. J. China Coal Soc. 2020, 45, 3696-3708.

8. Wang, F.T.; Shang, J.J.; Zhao, B.; Cao, Q.H. Surrounding rock structural characteristics and its anchor-cable strengthened support technology for the gob-side entry retaining with roof cutting and pressure releasing. Chin. J. Rock Mech. Eng. 2021, 40, 1-10. [CrossRef]

9. He, M.C.; Wang, Y.; Yang, J.J.; Gao, Y.B.; Gao, Q.; Wang, S.B. Zonal characteristics and its influence factors of working face pressure using roof cutting and pressure-relief mining method with no pillar and roadway formed automaticly. J. China Univ. Min. Technol. 2018, 47, 1157-1165.

10. Wang, J.; Zhu, D.Y.; Gong, W.L.; He, M.C.; Gao, R. Physical simulation experiment on the movement of rock strata upon automatic roadway forming by roof cutting and pressure releasing. Chin. J. Rock Mech. Eng. 2018, 37, 2536-2547.

11. Liu, X.; Hua, X.Z.; Yang, P.; Huang, Z.G. A study of the mechanical structure of the direct roof during the whole process of non-pillar gob-side entry retaining by roof cutting. Energy Explor. Exploit. 2020, 38, 1706-1724. [CrossRef]

12. Liu, X.; Hua, X.Z.; Huang, Z.G.; Yang, P.; Yang, S.; Chang, G.F. Dynamic instability mechanism of rock mass collapse with large structural plane under stress wave. Chin. J. Rock Mech. Eng. 2021, 40, 1-12. [CrossRef]

13. Hua, X.Z.; Chang, G.F.; Liu, X.; Sun, B.J.; Yang, S.; Wang, E.Q.; Li, C. Three-Dimensional Physical Simulation and Control Technology of Roof Movement Characteristics in Non-Pillar Gob-Side Entry Retaining by Roof Cutting. Shock Vib. 2021, 2021, 7491414. [CrossRef]

14. Gao, Y.B.; Yang, J.; He, M.C.; Wang, Y.J.; Gao, Q. Mechanism and control techniques for gangue rib deformations in gob-side entry retaining formed by roof fracturing in thick coal seams. Chin. J. Rock Mech. Eng. 2017, 36, 2492-2502.

15. Chen, Y.; Hao, S.P.; Chen, Y.T.; Zhang, Z.Z.; Wu, L.F.; Liu, H.L. Study on the application of short-hole blasting with guide hole to roof cutting pressure relief of gob-side entry retaining. J. Min. Saf. Eng. 2015, 32, 253-259.

16. Zhang, B.S.; Wang, P.F.; Cui, S.Q.; Fan, M.Z.; Qiu, Y.M. Mechanism and surrounding rock control of roadway driving along gob in shallow-buried, large mining height and small coal pillars by roof cutting. J. China Coal Soc. 2021, 46, 2254-2267.

17. Su, C.; Gong, P.L.; Kang, H.P.; Li, C.; Yi, K.; Liu, C.; Li, P. Mechanism of roof cutting and pressure relief in gob-side and high-stress roadway in deep coal mine. J. Min. Saf. Eng. 2020, 37, 1104-1113.

18. Xue, W.F.; Wang, S.J.; Huang, K.J.; Ji, R.J.; Liu, M.L.; Ren, Y.L.; Xi, X.P.; Wang, F. Theoretical analysis and field measurement of floor failure in gob side entry of cutting roof in confined water mine area. J. China Coal Soc. 2020, 45, 581-588. 
19. Yang, J.; Wei, Q.L.; Wang, Y.J.; Gao, Y.B.; Hou, S.L.; Qiao, B.W. Roof deformation mechanism and control measures of pillarless mining with gob-side entry retaining by roof cutting and pressure relief. Rock Soil Mech. 2020, 41, 989-998.

20. Yang, H.Y.; Li, Y.; Liu, Y.B.; Cao, S.G.; Pan, R.K.; Wang, H.; Wang, B.; Chen, X. Structure evolution and stability control mechanism of hard-roof cutting for roadway retaining. J. Min. Saf. Eng. 2021, 38, 766-773.

21. Lin, J.; Guo, K.; Sun, Z.Y.; Wang, T. Study on fracturing timing of hydraulic fracturing top-cutting and pressure relief in roadway with strong dynamic pressure. J. China Coal Soc. 2020, 48, 1-9. [CrossRef]

22. Wang, X.G. Blasting Manual; Metallurgical Industry Press: Beijing, China, 2010; pp. 263-364.

23. Dai, J. Blasting Engineering; Mechanical Industry Press: Beijing, China, 2021; pp. 126-251.

24. Duan, F.B. Engineering Blasting; Peking University Press: Beijing, China, 2012; pp. 149-267.

25. Xu, J.L.; Qian, M.G. Method to distinguish key strata in overburden. J. China Univ. Min. Technol. 2000, $29,463-467$.

26. Li, Y.F.; Hua, X.Z.; Wang, X.H.; Yang, K. Dynamic weight classification and differentiated support on mining roadway in Wanbei minefield. J. Min. Saf. Eng. 2017, 34, 1042-1050.

27. Liu, Z.H.; Yang, L.S.; Song, X.M.; Zhao, Y.S.; Feng, Z.C.; Yang, D. Stress control of deep cutting along roadway over roof rock. J. Min. Saf. Eng. 2014, 31, 347-353. 